\title{
Two Birds, One Stone-Reframing Cooking Energy Policies in Africa and Asia
}

\author{
Simon Batchelor ${ }^{1,2, *}$, Ed Brown $^{2}{ }^{\circledR}$, Nigel Scott ${ }^{1}$ and Jon Leary ${ }^{1,2}$ \\ Gamos, Reading RG1 4LS, UK; researchnigel@gamos.org (N.S.); jon.k.leary@gmail.com (J.L.) \\ 2 School of Social Sciences, Loughborough University, Loughborough LE11 3TU, UK; E.D.Brown@lboro.ac.uk \\ * Correspondence: research@gamos.org; Tel.: +44-118-9267039
}

Received: 25 March 2019; Accepted: 22 April 2019; Published: 26 April 2019

\begin{abstract}
For the past 40 years, the dominant 'policy' on cooking energy in the Global South has been to improve the combustion efficiency of biomass fuels. This was said to alleviate the burdens of biomass cooking for three billion people by mitigating emissions, reducing deforestation, alleviating expenditure and collection times on fuels and increasing health outcomes. By 2015, international agencies were openly saying it was a failing policy. The dispersal of improved cookstoves was not keeping up with population growth, increasing urbanisation was leading to denser emissions and evidence suggested health effects of improved stoves were not as expected. A call was made for a new strategy, something other than 'business as usual'. Conventional wisdom suggests that access to electricity is poor in Sub-Saharan Africa (SSA), that it is too expensive and that weak grids prevent even connected households from cooking. Could a new strategy be built around access to electricity (and gas)? Could bringing modern energy for cooking to the forefront kill two birds with one stone? In 2019, UK Aid announced a multi-million-pound programme on 'Modern Energy Cooking Services' (MECS), specifically designed to explore alternative approaches to address cooking energy concerns in the Global South. This paper outlines the rationale behind such a move, and how it will work with existing economies and policies to catalyse a global transition.
\end{abstract}

Keywords: biomass cooking; SDG 7; grid extension; off-grid electricity; renewable energy; climate change policies

\section{Introduction}

This paper describes how a new UK Aid programme (April 2019) will be seeking to intentionally change international energy policy and enable a significant transition in energy use. The programme is new and has yet to prove itself, however, the analysis presented in the paper illustrates how it is constructed to reframe the problem, build new networks, develop capacities to respond to emerging technologies and system models and to build institutional capacities to redirect resources to the proposed strategy, i.e., to intentionally enable the transition of policies.

The paper starts by outlining the problem. The challenges of biomass-based cooking are well known in the development community, yet three billion people still cook with biomass. At the same time, advances in modern energy access (often synonymous with electricity), while not yet on track for reaching the international community's aspirations for Sustainable Development Goal 7, have made significant gains and currently substantially fewer people (one billion) do not have access. The implication of these two headline statistics is that approximately two billion people have access to modern energy, mainly electricity, but are not cooking with it. The paper goes on to acknowledge that international agencies are saying that 'business-as-usual' in the cooking sector is failing and are calling for an alternative strategy. 
Against this backdrop, international researchers are exploring the emerging possibilities. Building on piecemeal research to date, in April 2019, UK Aid announced a multi-million-pound programme on 'Modern Energy Cooking Services' (MECS), specifically designed to explore alternative approaches and policies for addressing cooking energy concerns in the Global South. With alliances across a number of international agencies and high-level policy support, the programme will explore new strategies-something other than 'business as usual'. This paper outlines the rationale behind such a move, what this might mean for economies in transition, and the policy implications it may create.

After a short section outlining some of the recent data and evidence on cooking with electricity, (particularly in Sub-Saharan Africa), the paper then presents the Steven framework [1] with its five guidelines for intentionally influencing policy, and shows how the new UK Aid programme fits such a framework. It shows how the workstreams are designed to fulfil the framework, and how the future planned work will focus on 'changing the narrative'. Figure 1 highlights how factors that have driven previous work on improved cookstoves have been augmented by more recent trends, opening up new opportunities. The programme will intentionally seek to reframe the problem as one of how to facilitate the international community to more effectively integrate their agendas of climate change, increased access to modern energy and the alleviation of the burdens of cooking with biomass.

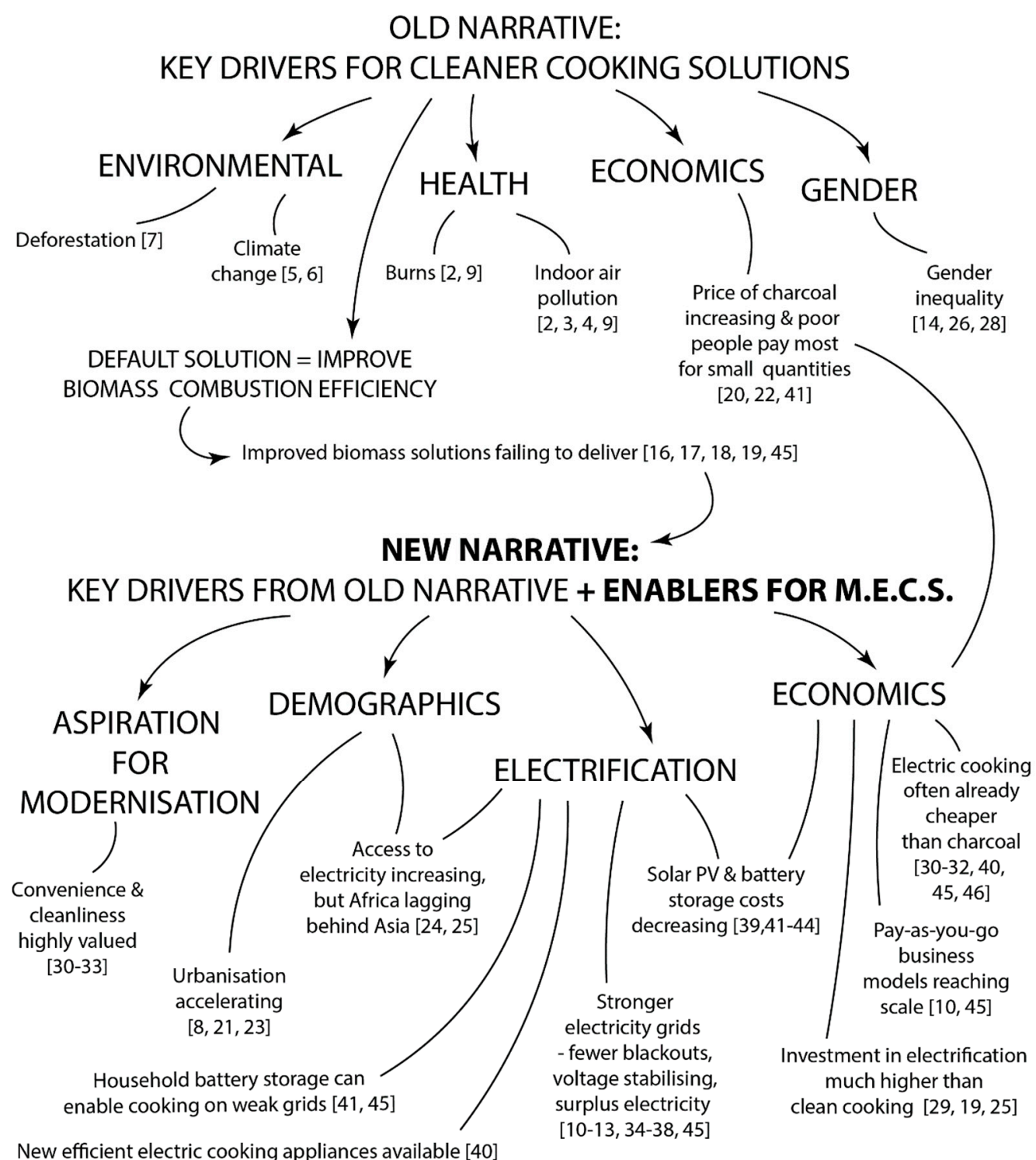

New efficient electric cooking appliances available [40]

Figure 1. Graphical overview of sources and flow of argument. 


\section{Three Billion}

Worldwide, nearly three billion people rely on traditional fuels (such as wood or charcoal) and technologies for cooking and heating. This has severe implications for health, gender relations, economic livelihoods and the environment, both at a global and local level.

According to the World Health Organization (WHO), household air pollution from cooking with traditional solid fuels contributes to between three and four million premature deaths every year [2] - more than malaria and tuberculosis combined [3,4]. Women and children bear much of the burden of collecting firewood or other traditional fuels and are disproportionally affected by health impacts.

The burning of non-renewable biomass fuels alone generates a gigaton of $\mathrm{CO}_{2} \mathrm{e}$ per year $(1.9 \%-2.3 \%$ of global emissions) [5]. The short-lived climate pollutant, black carbon, results from incomplete combustion and is estimated to add the equivalent of another $25 \%-50 \%$ of the global warming caused by carbon dioxide. Residential solid fuel burning is responsible for a quarter of global black carbon emissions [6]. Up to $34 \%$ of biomass fuel harvested is unsustainable [7], contributing to climate change and local forest degradation. Concentrated in South Asia and East Africa, approximately 275 million people live in biomass fuel depletion 'hotspots' - where demand exceeds natural supply and is unsustainable [7].

Africa's cities are growing-another Nigeria will be added to the continent's total urban population by 2025 [8] and urban centres are set to double in size over the next 25 years, reaching one billion people by 2040. Within urban and peri-urban locations, much of Sub-Saharan Africa continues to use purchased traditional biomass and kerosene for their cooking. Whilst kerosene used to be seen as an important transition fuel, the risk of burns and the health impacts of inhaling the noxious vapours have led the WHO to reclassify it as a polluting fuel [9]. Liquid Petroleum Gas (LPG) has had some penetration within urban conurbations, however, the supply chain is often weak, resulting in strategic fuel stacking with traditional fuels. Even where electricity is in use for lighting and other amenities, it is rarely used for cooking (with the exception of South Africa, where somewhat ironically it is mainly generated from coal-based power stations) [10-13]. Global commitments to rapidly increasing access to reliable and affordable modern energy need to include cooking services, or else household and localised air pollution will continue to significantly erode the well-being of communities.

A significant economic burden on households either in the form of time or expenditure is created where traditional biomass fuels are used, either collected in rural areas or purchased in peri-urban and urban areas. McKinsey Global Institute [14] states that much of women's unpaid work hours are spent on fuel collection and cooking. The report explores the economic potential available if the global gender gap embodied in such activities were to be closed. The findings show that if women were able to more fully participate in the labour market, as much as $\$ 28$ trillion, or $26 \%$, could be added to global annual GDP in 2025. Access to modern energy services could potentially redress some of this imbalance and release time into the labour market. Women can also play a key role in catalysing the efficient clean cooking and heating market for fuels and stoves. They can influence the design and uptake of products and engage in income-generating opportunities along the value chain.

To address this global issue and increase access to modern energy cooking service on a large scale, investment needs are estimated to be at least US $\$ 4.4$ billion annually [15]. Despite some improvements in recent years, this cross-cutting sector continues to struggle to reach scale and remains the most unlikely SE4All target to be achieved by 2030 [16], as well as one of the biggest challenges in delivering Sustainable Development Goal (SDG) 7, namely: Access to affordable, reliable, sustainable and modern energy for all. This lack of progress has wider implications, since enhanced access to modern energy cooking services, as a key part of SDG 7, is in a unique position to support progress across nine of the other SDGs: 
- SDG 1 No Poverty. Clean cooking is part of the basic services necessary to lead a healthy and productive life and saves households time and money.

- SDG 2 Zero Hunger. Affordable and convenient cooking reduces the time and money needed to cook, thus increasing the likelihood that families will be able to fit in cooking amongst their many other daily priorities.

- SDG 3 Good Health and Well-being. If smoke emissions from cooking are reduced it decreases the burden of disease associated with household air pollution and improves well-being, especially for women and children.

- SDG 4 Quality Education. Children, particularly girls, are often kept out of school so that they can contribute to household tasks, in particular cooking and collecting fuel.

- SDG 5 Gender Equality. Unpaid work, including collecting fuel and cooking, remain a major cause of gender inequality.

- SDG 8 Decent Work and Economic Growth. Energy access enables enhanced productivity and inclusive economic growth. The clean cooking sector offers many job opportunities.

- SDG 11 Sustainable Cities and Communities. Clean cooking addresses household and ambient air pollution, resource efficiency and climate vulnerability.

- SDG 13 Climate Action. Clean cooking solutions address the most basic needs of the poor, while also delivering climate benefits-up to $25 \%$ of black carbon emissions come from burning solid fuels for household energy needs.

- SDG 15 Life on Land. Up to 34\% of biomass fuel harvested for cooking and heating is unsustainable, contributing to forest degradation, deforestation and climate change.

\section{The Trouble with 'Business-As Usual' in Biomass-Based Cooking}

"While there has been some progress on access to clean cooking, our analysis shows that by 2030 2.3 billion people will still lack access to clean cooking facilities, with 2.5 million premature deaths each year still attributable to the resulting household air pollution". (This figure has been revised upward to 4 million by the WHO in 2018 [2].) "If we are to witness the kind of progress expected on electricity, clean cooking must be placed on a par with electricity access on the policy agenda. Women spend on average $1.4 \mathrm{~h}$ a day collecting fuelwood and four hours for cooking and also suffer the most from household air pollution: they must be at the heart of finding solutions" [17] (our emphasis).

In the context of these massive challenges and opportunities, the International Energy Agency/World Bank SE4All 2017 Global Tracking Framework [18] states that "the number of people who still use traditional, solid fuels to cook rose slightly to 3.04 billion, indicating that efforts to advance clean cooking are not keeping up with population growth". In addition to the SE4All report, ESMAP and GACC conclude that "the 'business-as-usual' scenario for the sector is encouraging" (without major new interventions about 180 million households globally will gain access to, at least, minimally improved cooking solutions by the end of the decade) "but will fall far short of potential" [19]. It notes that without major new interventions global targets will not be reached. Against this backdrop, the authors and the UK Aid team argue that we need to try a different approach, aimed at accelerating the uptake of truly 'clean' cooking.

Where fuel must be purchased, the increasing cost of charcoal, and in some cases fuel wood, place a burden on poor and vulnerable families struggling to meet basic needs. Time spent on collecting fuel-mostly by women — could be better spent on income generation, farming, education, childcare or leisure. Carrying heavy bundles of wood, often over long distances, can cause injuries and can put girls and women at risk of gender-based violence. Access to modern energy cooking services could redress some of this imbalance and release their time into the labour market. 
In Sub-Saharan Africa (SSA) for example, the poorest households often pay a premium for their daily fuel purchases ( $45 \%$ on average for the urban poor) due to cash flow constraints, and they allocate a significant proportion of their overall household expenditures to cooking fuels such as charcoal [20].

In Uganda for example, in 2017 charcoal prices increased by almost 30\% (in a country where inflation is less than $10 \%$ ) relative to the previous year. On average a household today spends as much as $\$ 24$ for a $75 \mathrm{~kg}$ bag of charcoal, which lasts about a month. Many others pay higher premiums for purchasing smaller quantities. The rising prices have to do in part with the increasing distances for transporting the fuel from its source to urban areas. Households are thus spending a significant and growing share of their monthly incomes on biomass fuels.

The biomass reliability problem is worsening due to population growth and rapid urbanisation. SSA annual average population growth rate is about 2.7\% [21]. Due to population growth outpacing the adoption of clean cooking solutions, some countries are registering backward progress in terms of uptake of clean cooking solutions. The fast pace of urbanisation also means that households are often switching from collecting fuelwood in rural areas to purchasing biomass fuels from peri-urban and urban markets. A recent finding shows that a $1 \%$ rise in urbanisation can increase charcoal consumption by $14 \%$ [22]. The average annual rate of urbanisation (2017) in SSA is $4.1 \%$, and in some countries is as high as 5.7\% [21]. At these rates the population currently living in African cities-about 472 million people, is expected to double by 2050 [23]. This phenomenon clearly requires that a more rapid transition from solid fuels to clean and more sustainable fuels needs to take place very soon.

\section{One Billion}

There is evidence of progress towards SDG7. However, it tends to be uneven across the globe. In 2017 the IEA (International Energy Agency) reported a fall of 97 million compared to 2016 in the number of people without electricity access, which brought the total to below one billion [24]. However, three-quarters of the 570 million people who gained access since 2011 are concentrated in Asia [24].

Many of those who have access to electricity do not have access to modern energy for cooking. The IEA report differentiates between access to electricity, access to clean cooking, renewable energy and energy efficiency. They note that in 2017, "nearly 2.7 billion people do not have access to clean cooking facilities, relying instead on biomass, coal or kerosene as their primary cooking fuel." Figure 2 shows that there is an emerging opportunity to leverage the progress made in electrification to facilitate the transition from biomass (and kerosene) to modern cooking energy services. In 2000, there were already 1.7 billion people with access to electricity, but lacking access to clean cooking. By 2016, this number had risen to 2.1 billion and this is predicted to rise to 2.2 billion in 2030 . It should be noted that despite both reportedly using data from the SE4All Global Tracking Framework (GTF), the IEA [24] and the World Bank [25] differ slightly on their statistics regarding electricity and clean cooking access. However, the trends are the same: rapid progress is being made in electrification, whilst clean cooking is struggling to keep up with population growth, resulting in increasing numbers of people with access to electricity, but without clean cooking (Figure 2). 


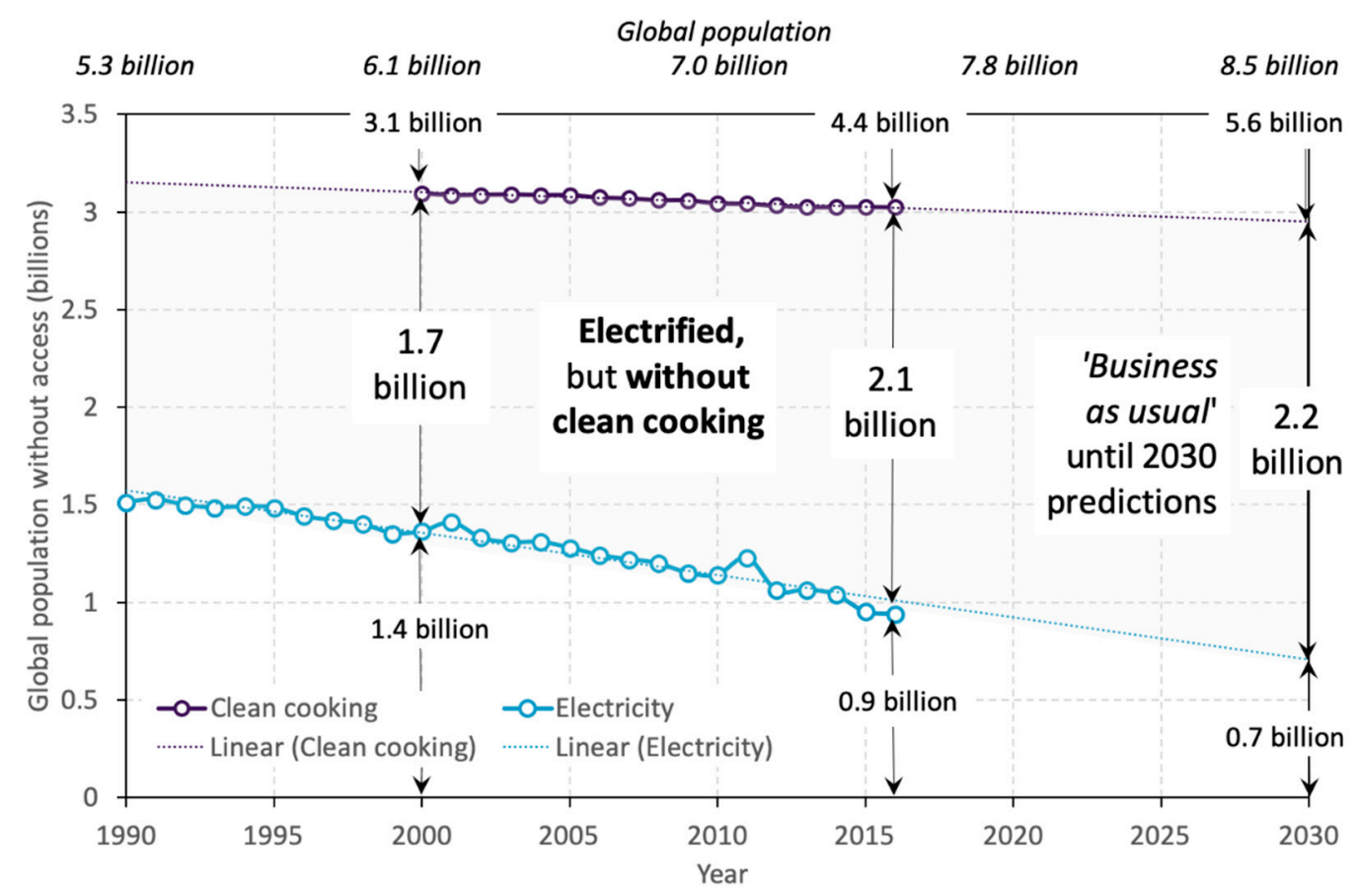

Figure 2. Trends in global access to electricity and clean cooking. Historical electrification, clean cooking and global population data sourced from the World Bank's World Development Indicators (WDI) [25]. Future population predictions sourced from United Nations World Population Prospectus [26]. Linear forecasting used to predict global access beyond 2016.

Expressing similar concern over the continuation of 'business as usual' approaches, the World Bank [27] note that 22 countries in the Africa Region have less than $25 \%$ access to electricity. Of those, 7 have less than $10 \%$ access. Their tone is pessimistic, in line with much of the recent literature on access to modern energy services and the achievement of SDG7. They argue that population growth is likely to outstrip new supplies and that "unless there is a big break from recent trends the population without electricity access in Sub-Saharan Africa is projected to increase by 58 percent, from 591 million in 2010 to 935 million in 2030." They lament that about 40\% of Sub-Saharan Africa's population is under 14 years old and conclude that if the current level of investment in access continues, "yet another generation of children will be denied the benefits of modern service delivery facilitated by the provision of electricity" [27].

Once again, the language is a call for something other than business as usual. The document calls for the Bank Group's energy practice to adopt a new and transformative strategy to help client countries orchestrate a national, sustained, sector-level engagement for universal access to electricity.

It is not that the world is not concerned with the two problems of biomass cooking and lack of access to modern energy. It is that currently policy and private sector actors are treating these as two separate problems. In this paper we explore how the use of modern energy for cooking services could not only provide a means of achieving rapid transitions to truly clean cooking amongst households in developing countries but could also provide crucial new business models for those promoting increased access to electricity.

Analysis of SDG 7 separates out access to electricity and access to clean cooking, because until recently, modern energy for cooking has just not been scalable. The growth of LPG over the last 10 years has been remarkable and is discussed below. However, the use of electricity for cooking among the population 'without access to clean cooking' has been remarkably low. Some would argue that this separation of 'access to energy' (which usually means electricity) and 'cooking' is based on gendered attitudes. Some researchers would argue that there has been a lack of attention in the past to household energy, reflecting that it has a particular importance to women and it is men who 
are making decisions $[28,29]$. They suggest this is reflected in investments in energy, citing a World Bank report on its investments in energy access over the period 2000-2008 [30]. This found that the support for promoting the transition to modern cooking fuels was quite small-less than $5 \%$ of total lending. The physical investment in electricity access accounted for nearly half of energy access related assistance. However, recent analysis by the World Bank and others has led to a call for increased investment in clean cooking, new strategies and joined up thinking between electricity access and other forms of modern energy for cooking [19,27].

Before examining that claim in more detail, and whether it continues to manifest in 2019, we need to acknowledge the final two foci of SDG7, the increasing share of renewable energy, and increasing energy efficiency [24]. The world is not on track to achieve the target on renewables. There is a call for acceleration. Nevertheless, there was an increase in the share of renewables in the total consumption, up a percentage point since 2010. As is to be expected, the response to the call for greater energy efficiency is also uneven. In the majority of developed countries, peak energy use occurred between 2005 and 2010. While the majority of countries have declining primary energy intensity (with China leading the way), some countries in Africa and South America are seeing an opposite trend.

How then do these trends affect the hopes, aspirations and wishes of women, children and men in developing countries regarding cooking their meals? How might this 'set of international policy foci' be influenced?

\section{How Do Electricity and Cooking Match in Sub-Saharan Africa?}

Before looking at the policy influencing side of things, we should first consider briefly the opportunity for matching modern energy with cooking services in SSA and Asia. Are there possibilities for utilising modern energy, particularly electricity, for creating something other than 'business as usual' with incremental improvements to biomass responses?

\subsection{The Emerging Opportunities of Grid Electricity Capacity}

Cooking with electricity could present a disruptive and transformative value proposition for households, allowing for more efficient and faster cooking times, adjustable heat levels, safer cooking and absence of dangerous indoor emissions, as well as a visibly cleaner cooking environment. Focus group discussions in four countries emphasise the aspirational nature of electric cooking, and the focus by the consumer on the cleanliness of the process-no soot, less spillage, less burnt food and less sweat, which leaves clothes clean at the end of the process [31-34].

To date, grid electricity in Africa and some parts of Asia has had generation, transmission and infrastructure challenges, that would in general preclude cooking with electricity. At the household level, issues surrounding weak grids include load shedding, voltage instability (brown-outs), localized wiring and network failures. Certainly not all African electricity grids are currently strong enough to support electric cooking. However, emerging changes in specific geographies and countries suggest new opportunities are arising.

In some contexts, there is now excess electricity, not yet utilised by existing demand. For instance, in terms of electricity generation capacity, several East African countries are currently on course to substantially increase their installed capacity. This is driven by long-term economic growth ambitions and provides an opportunity to expand electrical demand. Recent installations in Uganda have increased generating capacity to $950 \mathrm{MW}$, creating a generating surplus, for the moment. Power Africa has identified a further $1900 \mathrm{MW}$ of projects for completion by 2030. The World Bank estimate that not only will generating capacity in Kenya double from 2,300 MW in 2015 to 5000 MW in 2020, but the share of renewables will also increase from $65 \%$ to $84 \%$ [35]. Generating capacity in Tanzania was roughly $1500 \mathrm{MW}$ in 2017 [36], and with a further $1600 \mathrm{MW}$ planned, this capacity is projected to double imminently [37]. More recently, the Stiegler's Gorge hydropower project has been given the go-ahead, which will bring an additional $2100 \mathrm{MW}$ online [37], so the government's aim to reach 
5000 MW by 2020 [38] appears feasible. The government's Better Results Now initiative (2013) contains a longer term ambition to reach 10,000 MW by 2025 [39].

This increase in generating capacity is encouraging but does not suggest that transmission and infrastructure issues have been solved, nor that management issues within the private and public sector including utilities have been resolved. However, in many countries, the increased generation does suggest that electric cooking could be considered to stimulate demand. As stated above, in many countries electric cooking has become affordable when compared to charcoal costs, so if other weak grid factors could be overcome or mitigated (e.g., by well-planned infrastructure in new housing estates), then cooking with electricity would become viable. Researchers undertaking a global review of price data suggest that even when utilizing an inefficient hotplate there are a number of African countries where it is affordable to switch to electric cooking (notwithstanding the weak grid and access issues) [40]. When efficient appliances are considered (discussed below) more countries arise as possibilities from an affordability point of view [41].

\subsection{Off-Grid and Energy Storage}

There is a growing body of research in modern energy cooking services led by the UK $[40,42-45]$ that is investigating how to rapidly accelerate transition to genuinely 'clean' cooking with off-grid renewable energy. They argue that advances in solar photovoltaics, new battery technologies and innovative 'pay as you go' business models are opening up new opportunities for transitioning the way people cook. This ground-breaking research and innovation commissioned by the Department for International Development (DFID) has looked at the potential for solar electric cooking (solar panels combined with battery, heating appliance; control panels) as a clean, modern energy option for poor households. The promising research, known as 'eCook', signalled that cooking from renewables was technically viable and adaptable to standalone and mini-grid situations. Preliminary economic modelling found that by 2020 the monthly discounted cost of an eCook system could be of the same order as household expenditure on purchased charcoal [42]. Charcoal has considerable challenges in its supply chain, leading to increasing prices, and policies in a number of African countries seek to regulate and limit charcoal production.

Batchelor et al. [46] proposed that battery storage can also have an important role in time-shifting cooking loads on electrical grids. They define 'Grid-eCook' as a battery/cooker combination that can be trickle charged when grid electricity is available. It overcomes many of the problems of weak grids, notably stabilising the voltage, reducing peak loads and enabling cooking during blackouts. The charging process draws small currents, thus avoiding the safety problems created by poor quality wiring that could burn out with high current. Indeed, combined with the use of smart meters, or a controllable sim card built into the device, Grid-eCook could also be controlled by utilities to smooth out demand in real time and ensure that systems are only charged when surplus energy is available (e.g., at night). Of course, development of battery-supported cookers amongst grid-connected households, where ability to pay is higher and the logistical challenges are lower, should raise awareness of this new technology and strengthen both supply chains and local capacity to support the roll out of 'PV-eCook' (solar electric cooking) into the harder to reach off-grid rural areas.

\subsection{The Role of Energy Efficiencies}

Between 1970 and 2018 the average consumption of energy for cooking in UK households halved. Households in the UK cook with multiple appliances with about half using gas as the dominant fuel (for the bulk cooking) and half using electricity. The consumption has halved due to a number of factors: increasing efficiencies of the appliances, e.g., a fan-assisted oven uses considerably less than a conventional oven, and the use of precooked food, i.e., when food is sold in a partially cooked state, energy has been invested in it by the factory, and it reduces the household cooking energy consumption. This data draws attention to the potential that economies transitioning from biomass to electrical energy could leapfrog by utilising energy-efficient appliances. 
The authors have undertaken real world trials in Kenya, Tanzania, Zambia and Myanmar [31-33,47] to determine the energy consumption of meals cooked using electricity. Combined with stakeholder discussions, focus groups, and discrete choice modelling experiments, the data collected by 'cooking diaries' has given evidence of the potential energy, time and money savings associated with a range of electrical cooking equipment. While hotplates can cook 'tasty' meals with significantly less 'fuel' cost than charcoal (in urban centres), the savings are much greater with multicookers. This initial research has shown that these multicookers (or electric pressure cookers) can undertake more than $80 \%$ of the meal recipes that people prefer within the countries of study, including the main staples. For dishes such as beans or tripe that require boiling for several hours, multicookers have been measured to use approximately one fifth of the energy of a hotplate and in half the time. With added behavioural change such as soaking beans, energy savings can be considerably more. Multicookers could have a similarly transformative role for cooking as the LED has had for solar lighting systems.

The team have also identified efficiencies that are dependent on changes in behaviour that could be promoted. Lids, soaking beans overnight, cutting food into small pieces and not opening a pressure cooker to check whether the food is cooking, are all ways of saving energy. With biomass stoves, once a stove is lit, there are few incentives to try to save relatively small amounts of energy. However, the controllability of modern energy and its cost (or at least perceived cost), suggest that such savings may be important enough to generate behavioural change. Similarly, there may be room for more pre-cooking or partial cooking of food in urban settings to achieve efficiency gains by mass production, which could achieve a reduction in demand for cooking energy at the household level.

\section{Influencing International Development Policy}

If there are new emerging opportunities for modern energy in cooking, and in particular potential synergies between cooking and the agenda for improving and extending national grids and giving access to electricity by off-grid, then what could be done to influence this policy transition among the international community?

Batchelor [48] describes how the Steven Framework [1] was used to influence the international sector regarding Mobile Money. This was an intentional international policy influencing campaign during the 2000's [48]. The Steven Framework echoes and synthesizes many of the principles developed by work on research uptake such as the RAPID programme of ODI $[49,50]$ and IDRC [51,52]. As Batchelor [48] states:

"the emphasis has shifted towards a better understanding about how policy is shaped by multiple relations and reservoirs of knowledge. The traditional question that focused on 'How can research be better transported from the research to the policy sphere?' has been largely replaced by a more complex set of questions around 'Why are some ideas in circulation amongst researchers and policymakers picked up and acted on, while others are ignored and disappear?'. And, while there are many factors that affect the translation of research findings into policy recommendations, greater focus is now paid to the values, motivation, and power of different actors shaping the policymaking process."

The Stevens Framework is based on five guiding principles:

i. Changing perceptions and public opinion;

ii. Setting an agenda by reframing the way an issue is debated and creating pressure for change;

iii. Building networks that support delivery of change;

iv. Developing capacity within organisations to allow them to understand and respond to an issue;

v. Changing institutions, for example influencing strategy and resource allocations within organisations (often government but may be private sector).

Drawing on such insights and the Steven Framework in particular, UK Aid and the authors have developed a programme that at its heart will seek to 'change the narrative' of the cooking sector, to facilitate the international community to integrate more effectively the agendas on climate change, increased access to modern energy and the alleviation of the burdens of cooking with biomass. 
In response to the call for alternative strategies and for something other than the biomass-based 'business as usual', UK Aid has commissioned a new five year, multi-million-pound programme of work. The programme, Modern Energy Cooking Services (MECS) although only announced in April 2019, actually began work in October 2018, and where actions below are stated, they are the result of work building up to the commissioning of the programme or its inception phase. The following describes the programme, and how the components are designed to enable policy changes in energy access.

\subsection{Setting an Agenda by Reframing the Way an Issue Is Debated and Creating Pressure for Change (Steven [ii])}

The programme specifically aims to break out of this "business-as-usual" cycle by investigating how to rapidly accelerate a transition from biomass to genuinely 'clean' cooking (i.e., with electric or gas). Its strap line is "sparking a cooking revolution: catalysing Africa's transition to clean electric/gas cooking". It will do this by combining action on legislation, government policies, investments, private sector influencing, and changes in practice, perceptions or attitudes, or the language people use around an issue. In its clarity of purpose, it has said that while it will consider modern energy in various forms, such as biogas and ethanol, in addition to electricity and LPG, biomass is out of scope- even tier 4 biomass stoves. This clarity of purpose will be challenging, as biomass will no doubt be used for the next decade or more, and some stakeholders will ask why no action is being taken on Tier 4 stoves. However, as the programme seeks to re-orientate policies on cooking, it needs to be distinct and clear in its own purpose. While research on LPG and biogas have been a part of the agenda in the last few years, electricity for cooking (as an alternative to biomass) has been a neglected subject.

In particular, the main driver for the research is the idea that (renewably generated) electricity is going to reach a price point of affordability within a few years, with associated reliability and sustainability, that will open up completely new possibilities and markets. It will seek to integrate more effectively the agendas on climate change, increased access to modern energy and the alleviation of the burdens of cooking with biomass, so that cooking becomes seen as a key to unlocking modern energy access, enhancing grid extension and off-grid solutions.

\subsection{Developing Capacity within Organisations to Allow Them to Understand and Respond to An Issue (Steven [iv])}

The emerging opportunities are often based on broader advances in technology. Twenty years ago, pay as you go (PAYG) service provision would have been impossible in Sub-Saharan Africa, and even ten years ago, the absence of key components such as mobile money would have made it difficult. Now solar lighting in particular, but also water, grid electricity, LPG and other services can be provided on a PAYG basis, enabling poor households to pay week by week, or even day by day, in small, manageable expenditures. Today, the near ubiquity of mobile phone coverage opens up PAYG to even the remotest parts of SSA.

As such, the MECS programme will seek to work with organisations to co-create evidence and research and to uncover insights into the drivers and pathways for countries to transition to modern energy cooking services. This will include lab-based development and real-world testing of new technologies that make using electricity and gas more efficient, more practical, more desirable and more affordable for poor households. It will also include innovations in business models, financing and private sector delivery of modern energy cooking services. For instance, this programme brings together the early work, and will develop and refine the 'eCook' family of technologies described above, ensuring that it is underpinned by innovative business modelling and financing, as well as aligning them with cultural demands required for sustainable adaption.

The MECS programme will seek to increase capacity to provide reliable and affordable access to electric cooking services in areas where there is no grid, or the grid is weak. Additionally, it will enhance the viability of mini-grids, leading to increased access to modern energy from renewables. The time is right for MECS because of the dramatic fall in component prices, advances in technology, 
emergence of energy-efficient appliances, and the spread of mobile and PAYG payment systems that enable energy access for the poorest.

At the same time, there are substantial ground-breaking research opportunities in relation to LPG. Specifically, in relation to canister sizes, retail distribution networks, employer financing, PAYG and other innovative financing schemes, coupled with mobile technology data management systems. The team will also be investigating new cooking pots and pans that could considerably reduce gas consumption. There may also be a role for biogas as a genuinely clean fuel for cooking, where appropriate feedstock is available. Although biogas has had a chequered history of implementation in a development context, recent advances in technology may make it more accessible in some markets [53].

Beyond the technologies, this research will capture other drivers for transition including understanding and optimising fuel stacking, cooking demand and behavioural adaptation; and establishing the evidence base to support an enabling policy environment that will underpin a pathway to scale and support well understood markets and enterprises.

All of this is to develop the capacity within a wide range of stakeholders to understand that the world is changing, that the balance of affordability is changing and hopefully to develop the capacity of both the public and private sector to respond.

6.3. Changing Institutions, for Example Influencing Strategy and Resource Allocations within Organisations (Often Government, but May Be Private Sector). Stevens [v])

Building on previous programming and learning, but working towards a new strategy, the programme builds on earlier support by DFID (UK Aid) to the Global Alliance for Clean Cookstoves (GACC, now CCA) through the improved Evidence Base for Clean Cooking programme (EBCC). EBCC's focus (2011-2017) was predominantly on improving cookstoves utilising biomass-based fuels, i.e., the biomass 'business-as-usual'. Evidence gathered from that programme concluded that truly clean stoves and fuels are necessary to be effective at providing health and other benefits. As such, it will be important to make fuels such as LPG, ethanol and electricity more affordable and accessible to populations in developing countries. It also found evidence that tackling air pollution at the household level alone is insufficient to result in impactful health outcomes if only a few households in a community are using cleaner cookstoves and fuels, as this will have little impact on reducing ambient air pollution levels. This finding was strengthened by recent DFID, Medical Research Council (MRC) and Wellcome Trust financed research, which also found inconclusive evidence from current intervention approaches of improved health outcomes and called for alternative approaches to the enduring problem of cooking. EBCC also signalled that biomass cooking places a particular burden on women and children in terms of time and security when gathering fuel, cooking practices and household decision taking. EBCC stated clearly that cooking is a gender-based issue. These important experiences and lessons will be valuable to the MECS programme.

The above illustrates how gathering evidence has begun to lead to influence towards a change in strategy. However, it is important to note that despite considerable investment, the emerging strategy was not on the agenda over the last five years. For instance, UK Aid support to the World Bank-hosted Energy Sector Management Assistance Programme (ESMAP), through the Cities and Infrastructure for Growth (CIG) programme, has included a strand of work focused on broader sustainable modern energy initiatives, which to date has not included modern energy cooking.

A number of programmes led by DFID UK Aid work on clean sustainable energy, for example: the Moving Energy Initiative (MEI, humanitarian responses), Understanding Sustainable Energy Solutions (USES, a wide range of renewables research with UK academia) and Low Energy Inclusive Appliances (LEIA, energy efficiency for poor households, but until recently, excluding cooking) programmes. MEI and USES consider cooking as an issue, but there was no single programme that sought to address a system-wide view of the core drivers and barriers for a transition to modern energy cooking services at scale. This is what the MECS programme has been designed to deliver. 
Part of the long-term influencing strategy will include the generation of longitudinal data. To date, little research has been carried out on multiple attributes of a cooking energy service. National household survey data collection tends to ask about the primary fuel for cooking and does little to situate the cooking in context. Health is strongly affected by ventilation for instance, so policy actors have found it difficult to see the depth of the problem by only knowing that the primary fuel is, for instance 'charcoal'. The Multi-Tier Framework (MTF) is an approach promoted by the World Bank to provide policy actors with more comprehensive data, which will be embedded within national surveys. Research here aims to contribute to the development of a SDG indicator on access to modern energy cooking services, and feed into the global tracking of SDG7.

By generating new data on the nuances of the problem, by lobbying and co-creating new approaches, the programme will change institutions and the way their resources are allocated.

\subsection{Building Networks that Support Delivery of Change (Steven [iii])}

The programme works with a wide range of UK universities and innovators, the World Bank (ESMAP) and has drawn in the Clean Cooking Alliance (CCA, formerly GACC). While ESMAP and CCA have pre-existing networks within high level policy making, the bringing together of a wide range of academics and practitioners is intentionally creating new networks. Challenge and accelerator funds will be used to crowd in the private sector and to mitigate the risk to them of exploring the newly framed agenda - bringing together their experience of solar lighting, delivering utility services, being independent power producers and of setting up value chains, and applying it to emerging approaches to cooking. Meanwhile, academic teams are modelling whole national energy systems to determine the implications of encouraging the population to use the grid for cooking. Life Cycle Analysis (LCA) is included to ask the question of what happens to this technology at the end of its life (waste disposal of batteries has been raised as a potential problem for eCook)? Other researchers are innovation specialists, addressing the question of how can ongoing innovation keep an eye on technological developments and apply them as they emerge? Others are cultural specialists that will look at how behavioural change can both enable and constrain adoption and sustained use of modern energy cooking services.

Cooking is a deeply cultural experience, and each context will present its own unique challenges and opportunities. When biomass is used for cooking, there is considerably less control over the heating process than that offered by modern energy such as LPG or electricity. The greater control offered by electricity will require some behavioural change, which may act as a barrier. However, the ability to turn a stove on/off or up/down at the press of a button and then be able to go away and do other things, may act as a driver, encouraging new users to overcome their initial hesitations. For instance, focus groups in East Africa have speculated that more men might cook if cooking were made easier by electrical appliances [33].

New networks also include the programme's provision for 'experiments at scale'. The programme has already identified more than $\$ 300$ million of IDA (International Development Assistance) lending for electricity access that could be directly influenced to consider the relevance of cooking. Indeed, some senior World Bank staff have suggested that MECS is relevant to the Bank's entire \$3 billion of IDA lending for increasing electricity access. Indeed, one can see that even discussion of the programme is beginning to change the allocation of resources.

The reframing of the problem of cooking as more than biomass and inclusive of modern energy, particularly electricity, has effectively started to create new networks of interested stakeholders.

\subsection{Changing Perceptions and Public Opinion (Steven [i])}

In these early days of reframing the agenda, the programme has focused more on key stakeholders than the general public. 'Changing the narrative', is a workstream within the programme and includes intentional action to influence high level policy discussions. For instance, in 2017, the biennial Clean Cooking Forum organised and hosted by CCA, had a single session discussing alternative strategies. 
One discussant asked why such an important subject had seemingly been marginalized to the last day in a basement seminar room. In 2019 an entire thread of the Clean Cooking Forum will be discussing this alternative strategy-this is the 'changing narrative' that the MECS programme is seeking to stimulate. Similarly, Tanzanian parliamentarians have already been engaged, and made requests for more discussion and evidence on the role electricity might play in cooking both on grid and off-grid. Parliamentarians are also coming together through the Climate Parliament.

At the more 'public' level, an energy cookbook has been created for everyday Kenyan cuisine. To date, four Kenyan cooks have featured in the book, cooking a range of typical dishes, whilst researchers observed, recorded and compared energy consumption across various fuels and appliances. The recipe book illustrates how in Nairobi in 2019, cooking the most energy intensive dishes with electricity can cost one tenth of the fuel cost of cooking with charcoal. At the time of this paper's submission, this eCookBook had not yet been distributed, but it illustrates how the programme is working to change perceptions within the public.

\section{Discussion-The Role of Policy Contexts}

\subsection{Intentional Influencing is Informed by Existing Policy Contexts}

The above has illustrated how the new programme fits the framework offered by Steven to influence international policy environments. In terms of energy policy, it is perhaps important to place the new programme in the wider policy context of the UK. MECS aligns well with UK Government policy, DFID's strategic objectives, and the host departments (Research and Evidence Division's, RED's) operational plan. For instance, the DFID Single Departmental Plan has objectives on "promoting global prosperity and spend on economic development" and "tackling extreme poverty and helping the world's most vulnerable" - women and girls in particular have the most to gain from a transition to modern energy and genuinely clean cooking. UK Aid's strategy, Promoting Global Prosperity commits to "... unlock the potential to significantly scale up the household solar market, expanding energy access across sub-Sahara Africa" and government's commitment to "helping developing countries use clean energy" is contextually relevant.

Specific policy instruments such as the DFID Research Review generated commitment to significantly increase support for research and innovation into priority themes around "scaling up clean energy use" and "putting into use innovations". Additionally, harnessing technological innovation became a part of DFID's Strategic Directions work: "strategic R\&D investment to secure scientific breakthroughs for key development challenges" and "new approaches to scale transformative technologies."

With a focus on using clean energy and fuels for genuinely clean cooking, MECS will count as International Climate Finance and as part of the UK's commitment to Mission Innovation. MECS also contributes to the government's Manifesto Commitment to "work to prevent climate change and assist the poorest in adapting to it" and "providing UK leadership on research and innovation and contributing to global prosperity". Providing energy for clean cooking in humanitarian situations will contribute to the objectives around resilience and response to crisis.

These underlying commitments of the UK have enabled the UK to consider how it might lead in reframing the way the issue is debated.

\subsection{Intentional Influencing Demands a Focus on the Policy Contexts}

At the same time, the programme not only seeks to contribute to existing UK Aid related policies, but also to ensure that there are ever increasing policy environments conducive to inclusion of modern energy cooking services. It will be important that National Development Strategies and plans can evolve to include modern energy cooking services. As stated above, plans often discuss modern energy access but rarely include cooking services. When addressed, cooking is often mentioned as part of a biomass/forestry strategy, driving assumptions that biomass fuels are the only viable option for the 
poor. The market for LPG in the Global South has grown in the last ten years, however, policy options on utilising LPG remain piecemeal. Global advances in technology and business models supported by digital communication are enabling new approaches and opportunities. The groundwork for this programme suggests that modern energy cooking services will be increasingly affordable to the poor within a few years in many markets. There is an assumption that policy actors will be willing to adapt and change in response to new knowledge and learning on MECS. In particular, the programme has an output area that seeks to address issues around scaled response, and this is specifically intended to foment a policy environment conducive to inclusion of modern energy cooking services.

The programme also believes in market approaches, and that market environments need to be conducive to inclusion of modern energy cooking services. While policies may enable modern energy cooking services, it is the private sector who will ultimately drive and implement them. It will be important that the predicted price points are reached and that advances in energy storage (e.g., electric vehicles), renewable energy generation, energy efficiency and adaptive systems are leveraged. For the private sector to apply these advances, finance needs to be available for start-ups. This will be predicated on the context, growth and stability of the business environment and the ease of doing business. There is no one size of institution that may implement modern energy cooking services and new actors may form and evolve to deliver them. The programme includes the formation of business models and plans to attract investors and the private sector to modern energy cooking services. On the demand side it will be crucial that consumers respond positively, so the programme includes work on consumer preferences and how to address consumer aspirations.

To do this, the programme needs the availability of a range of financing mechanisms that are suitable for specific transition pathways. The transition theory of change will propose pathways by which modern energy cooking services may be taken up in specific countries or regional contexts, considering both supply and demand. A key condition for agencies and governments to go down the modern energy cooking services pathway will be the availability of finance and financial institutions willing to engage with these new opportunities. There will need to be suitable risk appetite among financiers both for soft financing at start up (mentioned above) and for the longer term at scale. As a result, the MECS programme has been designed to leverage the World Bank energy access IDA and promotes linkages to financiers, donors, governments and Non-Governmental Organisations (NGOs) with energy access programming.

\subsection{Intentional Influencing Needs to Keep in View Real People}

It is important to note relevant social policies. The role of women within the fuel chain and the burden of gathering and using biomass for cooking is central to the programme. Cooking with polluting fuels is currently a health, environmental, economic and wellbeing concern, which particularly affects women and children. In a consultation hosted by the international network on gender \& sustainable energy (Energia) and the LCEDN (Low Carbon Energy for Development Network), researchers drew attention to how modern energy cooking services could provide a clean, safe and socially acceptable cooking environment for women and would release their time for other activities. The programme has at its core, the well-being of women. The Multi-Tier Framework (MTF) indicators will track the effect of the change on women, and will work towards monitoring and fulfilling SDG7, as well as SDG5, which calls for greater gender equality. The programme will seek opportunities to engage women at all levels of research and implementation not just as beneficiaries. UK research has looked at the employment of women in technical and management roles in renewable energy services. The considerations and measures included in the operational framework of this programme are in line with the provisions made under the 2014 International Development (Gender Equality) Act.

In addition, in identifying the drivers and barriers to the uptake of modern energy cooking services, the teams will consider the role of disability and safe cooking. Biomass fuel collection can be an issue for those physically impaired, and the use of MECS will directly address this. It is well known that many adults in resource poor households have poor eyesight. While the programme 
will not tackle this core problem, it will take issues such as this into account by ensuring that simple mitigating steps like making switches and monitoring lights large, bright or tactile enough for people to know what their appliances are doing. Visual monitoring of the appliances might in some cases be supplemented with audible alarms-for instance with minimal extra cost, electrical appliances can have automatic shut offs and audible timers. Modern energy cooking services are also easier to light than biomass stoves, and so those with physical disabilities will likely see gains in their quality of life, and the programme team will keep these needs in mind when designing new and innovative systems. Since the programme proposes optimising the use of technology, the team will also address the question of age-whether older people can realistically operate modern cooking appliances. The programme will consider a challenge fund specifically on the adaptation of modern energy cooking services for the very vulnerable.

\section{Conclusions}

This paper has presented the international call for something other than 'business as usual' in energy for cooking. It has shown how agencies are saying that existing strategies are not working and how new strategies are needed. New direction in policy, including new transitions in energy policy, are not formed in a vacuum. The paper has shown how early piecemeal research was able to give a window on new opportunities, and how the wider policy context of the UK and its commitment to alleviating climate change, to alleviating poverty, to gender equality, to make 'strategic R\&D investment to secure scientific breakthroughs for key development challenges' and 'new approaches to scale transformative technologies' was able to create a space for a new programme with an alternative strategy. Core to this strategy is to crowd in stakeholders, to experiment at scale, and to ensure that local policy and market environments are conducive to change. To do this, the programme has set itself the task, alongside other international actors, to 'change the narrative'. To move the narrative away from the thought that biomass and solid fuels are the main solution for cooking energy, to one that explores and leverages interest and investment in modern energy. One that builds on the world's commitment to SDG7: "access to affordable, reliable, sustainable and modern energy for all [inclusive of cooking needs]" (our addition).

Author Contributions: Conceptualization, S.B., J.L., E.B. \& N.S.; methodology, S.B., J.L. \& N.S.; investigation, S.B., J.L., E.B. \& N.S.; writing—original draft preparation, S.B.; writing—review and editing, S.B., J.L., E.B. \& N.S.; visualization, J.L.; funding acquisition, S.B., E.B.

Funding: The research programme named is funded by UK Aid (GB-GOV-1-300123). The research that led to the programme and supports the argument in the paper was funded by EPSRC (EP/L022311/1) and InnovateUK (132724) with matching funds by Gamos Ltd., who also invested in the research as a public good.

Acknowledgments: The authors thank the myriad of people who have contributed to the background research utilised to plan the new strategies.

Conflicts of Interest: The authors declare no conflict of interest.

\section{References}

1. Steven, D. Evaluation and the New Public Diplomacy—Presentation to the Future of Public Diplomacy 842nd Wilton Park Conference; River Path Associates: Wimbourne, UK, 2007.

2. WHO Household Air Pollution and Health. Available online: https://www.who.int/en/news-room/factsheets/detail/household-air-pollution-and-health (accessed on 25 March 2019).

3. WHO Tuberculosis. Available online: https://www.who.int/en/news-room/fact-sheets/detail/tuberculosis (accessed on 25 March 2019).

4. WHO Malaria. Available online: https://www.who.int/en/news-room/fact-sheets/detail/malaria (accessed on 25 March 2019).

5. Bailis, R.; Drigo, R.; Ghilardi, A.; Masera, O. The carbon footprint of traditional woodfuels. Nat. Clim. Chang. 2015, 5, 266-272. [CrossRef] 
6. CCA Climate \& Environment. Available online: https://www.cleancookingalliance.org/impact-areas/ environment/index.html (accessed on 25 March 2019).

7. Rob, B.; Yiting, W.; Rudi, D.; Adrian, G.; Omar, M. Getting the numbers right: Revisiting wood fuel sustainability in the developing world. Environ. Res. Lett. 2017, 12, 115002.

8. Lall, S.V.; Henderson, J.V.; Venables, A.J. Africa's Cities-Opening Doors to the World; World Bank: Westminster, UK, 2017; Volume 15, ISBN 9781464810442.

9. WHO. Burning Opportunity: Clean Household Energy for Health, Sustainable Development, and Wellbeing of Women and Children; WHO: Geneva, Switzerland, 2016.

10. Brown, E.; Leary, J.; Davies, G.; Batchelor, S.; Scott, N. eCook: What behavioural challenges await this potentially transformative concept? Sustain. Energy Technol. Assess. 2017, 22, 106-115. [CrossRef]

11. Baker, L.; Newell, P.; Phillips, J. The Political Economy of Energy Transitions: The Case of South Africa. New Politic Econ. 2014, 19, 791-818. [CrossRef]

12. Cowan, B. Identification and Demonstration of Selected Energy Best Practices for Low-Income Urban Communities in South Africa; Alleviation of Poverty through the Provision of Local Energy Services (APPLES); Energy Research Centre, University of Cape Town: Cape Town, South Africa, 2008.

13. Balmer, M. Energy poverty and cooking energy requirements: The forgotten issue in South African energy policy? J. Energy S. Afr. 2007, 18, 4-9.

14. McKinsey Global Institute. The Power of Parity: How Advancing Women's Equality can add \$12 Trillion to Global Growth; McKinsey Global Institute: New York, NY, USA, 2015.

15. SE4All. Progress Toward Sustainable Energy 2015-Global Tracking Framework Report; SE4All: Washington, DC, USA, 2015.

16. IRENA. Tracking SDG7: The Energy Progress Report 2018; IRENA: Abu Dhabi, United Arab Emirates, 2018.

17. IEA. WEO-2017 Special Report: Energy Access Outlook; IEA WEO: Paris, France, 2017.

18. SE4All. Global Tracking Framework: Progress toward Sustainable Energy; SE4All: Washington, DC, USA, 2017.

19. ESMAP; GACC. State of the Global Clean and Improved Cooking Sector; ESMAP: Washington, DC, USA, 2015.

20. World Bank. Clean and Improved Cooking in Sub-Saharan Africa: A landscape Report; World Bank: Washington, DC, USA, 2014.

21. World Bank Urban Population Growth (Annual \%). Available online: https://data.worldbank.org/indicator/ SP.URB.GROW?locations=ZG (accessed on 25 March 2019).

22. Adam Smith International Black Gold-The Real Cost of Charcoal in Africa. Available online: https://medium. com/@adamsmithinternationa192/black-gold-the-real-cost-of-charcoal-in-africa-7d241a2f3084 (accessed on 25 March 2019).

23. Saghir, J.; Santoro, J. Urbanization in Sub-Saharan Africa. Meeting Challenges by Bridging Stakeholders; Center for Strategic and International Studies: Washington, DC, USA, April 2018.

24. IEA SDG 7. Available online: https://www.iea.org/sdg/ (accessed on 25 March 2019).

25. World Bank. World Development Indicators; World Bank: Washington, DC, USA, 2019.

26. United Nations. World Population Prospectus: The 2017 Revision, Key Findings and Advance Tables; United Nations: New York, NY, USA, 2017.

27. IEG World Bank Group. World Bank Group Support to Electricity Access, FY2000-2014-An Independent Evaluation; IEG World Bank Group: Washington, DC, USA, 2015.

28. Parikh, J.; Smith, K.; Laxmi, V. Indoor air pollution: A reflection on gender bias. Econ. Political Wkly. 1999, 34, 539-544.

29. Cecelski, E.W. From Rio to Beijing: Engendering the energy debate. Energy Policy 1995, 23, 561-575. [CrossRef]

30. Barnes, D.F.; Singh, B.; Shi, X. Modernizing Energy Services for the Poor: A World Bank Investment Review-Fiscal 2000-08; World Bank: Washington, DC, USA, 2010.

31. Leary, J.; Serenje, N.; Mwila, F.; Yamba, F.; Scott, N.; Batchelor, S.; Leach, M.; Brown, E. eCook Zambia Country Report: Opportunities and Challenges in Zambia (IN PREPARATION); Lusaka, Zambia, 2019; Available online: https://elstove.com/innovate-reports/ (accessed on 24th April 2019).

32. Leary, J.; Myint, A.; Hlaing, W.W.; Sane, S.; Soe, T.T.; Scott, N.; Batchelor, S.; Leach, M.; Brown, E.; Siew, K. eCook Myanmar Country Report: Opportunities and Challenges in Myanmar (IN PREPARATION); Yangon, Myanmar, 2019; Available online: https://elstove.com/innovate-reports/ (accessed on 24th April 2019). 
33. Batchelor, S.; Leary, J.; Sago, S.; Minja, A.; Sawe, E.; Shuma, J.; Scott, N.; Leach, M.; Brown, E. eCook Tanzania Country Report-Opportunities and Challenges in Tanzania; Dar es Salaam, Tanzania, 2018; Available online: https://elstove.com/innovate-reports/ (accessed on 24th April 2019).

34. Chepkurui, K.; Leary, J.; Numi, A.; Fodio-Todd, J.; Hanlin, R.; Batchelor, S.; Brown, E.; Scott, N. Nairobi eCookBook Focus Group Discussion-Final Report (IN PREPARATION); Nairobi, Kenya, 2019; Available online: https://elstove.com/ (accessed on 24th April 2019).

35. Power Africa. Development of Kenya's Power Sector 2015-2020; Power Africa: Nairobi, Kenya, 2015.

36. EWURA. Annual Report for the Year Ended 30th June 2016; EWURA: Dar es Salaam, Tanzania, 2017; Volume 255.

37. Eberhard, A.; Gratwick, K.; Kariuki, L. A review of private investment in Tanzania's power generation sector. J. Energy S. Afr. 2018, 29, 1-11. [CrossRef]

38. Export.Gov Tanzania-Energy. Available online: https://www.export.gov/article?id=Tanzania-Energy (accessed on 25 March 2019).

39. EEG. Tanzania Energy Sector Overview; Energy for Economic Growth Research Programme: Oxford, UK, 2016. Available online: https://www.gov.uk/dfid-research-outputs/tanzania-energy-sector-overview (accessed on 24 April 2019).

40. Leary, J.; Batchelor, S.; Leach, M.; Brown, E.; Alsop, A. eCook Global Market Assessment Where Will the Transition Take Place First? Implemented by Gamos, Loughborough University, University of Surrey. Funded by DfID, Innovate UK, Gamos; 2018; Available online: https://elstove.com/tag/global-market-assessment/ (accessed on 24 April 2019).

41. Batchelor, S.; Brown, E.; Leary, J.; Scott, N.; Alsop, A.; Leach, M. Solar electric cooking in Africa: Where will the transition happen first? Energy Res. Soc. Sci. 2018, 40, 257-272. [CrossRef]

42. Leach, M.; Oduro, R. Preliminary Design and Analysis of a Proposed Solar and Battery Electric Cooking Concept: Costs and Pricing; Evidence on Demand (prepared at the request of the UK Department for International Development); 2015. Available online: https://assets.publishing.service.gov.uk/media/ 57a08974e5274a31e00000b8/E-Cooking_RQ1_Final_231115.pdf (accessed on 24 April 2019).

43. Brown, E.; Sumanik-Leary, J. A Review of the Behavioural Change Challenges Facing a Proposed Solar and Battery Electric Cooking Concept; Evidence on Demand (prepared at the request of the UK Department for International Development); 2015. Available online: https://assets.publishing.service.gov.uk/media/ 57a9b2ffed915d096e000004/3_E-Cooking_RQ3_Final_171215.pdf (accessed on 24 April 2019).

44. Slade, R. Key Assumptions and Concepts on Potential for Solar Electric Cooking: Batteries Capable of Operating Suitably in 'Harsh" Conditions in the Developing World'; Prepared at the request of the UK Department for International Development; 2015. Available online: https:/assets.publishing.service.gov.uk/media/ 57a9f60640f0b608a700004f/30_E-cooking_RQ2_Final_170216.pdf (accessed on 24 April 2019).

45. Batchelor, S. Solar Electric Cooking in Africa in 2020: A Synthesis of the Possibilities; Evidence on Demand (prepared at the request of the UK Department for International Development); 2015. Available online: https://assets.publishing.service.gov.uk/media/57a08975ed915d3cfd00025a/Solar_Electric_ Cooking_Synthesis_Report.pdf (accessed on 24 April 2019).

46. Batchelor, S. Africa Cooking with Electricity (ACE); Gamos Working Paper (Draft as at August 2015); Gamos: Reading, UK, 2015; Available online: https://www.researchgate.net/publication/298722923_Africa_ cooking_with_electricity_ACE (accessed on 24 April 2019).

47. Scott, N.; Leary, J.; Hanlin, R.; Chepkemoi, M.; Batchelor, S. Kenya Cooking Diaries Final Report (IN PREPARATION); Nairobi, Kenya, 2019; Available online: http://www.sussex.ac.uk/spru/research/projects/ lct (accessed on 24 April 2019).

48. Batchelor, S. Changing the financial landscape of Africa: An unusual story of evidence-informed innovation, intentional policy influence and private sector engagement. IDS Bull. 2012, 43, 84-90. [CrossRef]

49. Tilley, H.; Shaxson, L.; Young, J.; Rea, J.; Ball, L. 10 Things to Know About How to Influence Policy with Research; Overseas Development Institute: London, UK, 2017.

50. Crewe, E.; Young, J. Bridging Research and Policy: Context, Evidence and Links; Overseas Development Institute: London, UK, 2002.

51. Carden, F. Issues in assessing the policy influence of research. Int. Soc. Sci. J. 2004, 56, 135-151. [CrossRef] 
52. Carden, F. Knowledge to Policy: Making the Most of Development Research; IDRC \& Sage: Ottowa, ON, Canada, 2018; Volume 31, ISBN 9788178299303.

53. Prasad, S.; Rathore, D.; Singh, A. Recent Advances in Biogas Production. Chem. Eng. Process. Tech. 2017, 3, 1038. article distributed under the terms and conditions of the Creative Commons Attribution (CC BY) license (http://creativecommons.org/licenses/by/4.0/). 